\title{
Primary care summary of the British Thoracic Society Guidelines for the management of community acquired pneumonia in adults: 2009 update
}

\author{
Endorsed by the Royal College of General Practitioners and the Primary Care \\ Respiratory Society UK
}

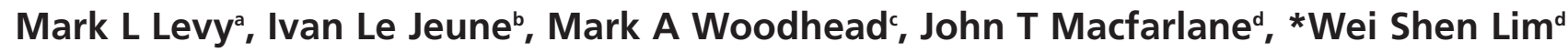 on behalf of the British Thoracic Society Community Acquired Pneumonia in Adults Guideline Group}

a Senior Clinical Research Fellow, Allergy and Respiratory Research Group, Division of Community Health Sciences: GP section, University of Edinburgh, Scotland, UK

${ }^{b}$ Departments of Acute and Respiratory Medicine, Nottingham University Hospitals NHS Trust, Nottingham, UK

c Department of Respiratory Medicine, Manchester Royal Infirmary, Manchester, UK

d Department of Respiratory Medicine, Nottingham University Hospitals NHS Trust, Nottingham, UK

Received 11th January 2009; revised version received 29th January 2010; accepted 1st February 2010; online 15th February 2010

\begin{abstract}
Introduction: The identification and management of adults presenting with pneumonia is a major challenge for primary care health professionals. This paper summarises the key recommendations of the British Thoracic Society (BTS) Guidelines for the management of Community Acquired Pneumonia (CAP) in adults.

Method: Systematic electronic database searches were conducted in order to identify potentially relevant studies that might inform guideline recommendations. Generic study appraisal checklists and an evidence grading from A+ to D were used to indicate the strength of the evidence upon which recommendations were made.

Conclusions: This paper provides definitions, key messages, and recommendations for handling the uncertainty surrounding the clinical diagnosis, assessing severity, management, and follow-up of patients with CAP in the community setting. Diagnosis and decision on hospital referral in primary care is based on clinical judgement and the CRB-65 score. Unlike some other respiratory infections (e.g. acute bronchitis) an antibiotic is always indicated when a clinical diagnosis of pneumonia is made. Timing of initial review will be determined by disease severity. When there is a delay in symptom or radiographic resolution beyond six weeks, the main concern is whether the CAP was a complication of an underlying condition such as lung cancer.

(C) 2010 Primary Care Respiratory Society UK. All rights reserved.

ML Levy et al. Prim Care Resp J 2010; 19(1): 21-27.

doi:10.4104/pcrj.2010.00014
\end{abstract}

Keywords community acquired pneumonia, primary care, guideline, adults, diagnosis, severity, management, CRB-65 score, treatment, follow-up

\section{Introduction}

General practitioners (GPs) are faced with patients who present many different types of medical, social and general problems. A typical consultation in general practice involves identifying the patient's presenting problem, hypothesising possible aetiologies, examination, performing and arranging investigations, decisions on further management, addressing preventative medical issues, and sometimes referral for specialist advice or care - all within time slots of 6 to 12 minutes. ${ }^{1}$ Another challenge is to identify those patients in need of immediately necessary treatment as opposed to those who could be investigated and treated over a number of subsequent consultations.

\footnotetext{
* Corresponding author: Dr Wei Shen Lim, Consultant Respiratory Physician, Department of Respiratory Medicine, David Evans Building, Nottingham University Hospitals NHS Trust, Hucknall Road, Nottingham, NG5 1PB, UK. Tel: +44 (0)115 9691169 ext 59347 Fax: +44 (0)115962 7723 E-mail: weishen.lim@nuh.nhs.uk
} 
ML Levy et al.

\section{Table 1. Brief description of the generic levels of evidence and guideline statement grades used.}

\begin{tabular}{lll} 
Evidence level & Definition & Guideline statement grade \\
\hline Ia & A good recent systematic review of studies designed to answer the question of interest & A+ \\
Ib & One or more rigorous studies designed to answer the question, but not formally combined \\
III & One or more prospective clinical studies which illuminate, but do not rigorously answer, the question \\
IVa & One or more retrospective clinical studies which illuminate, but do not rigorously answer, the question \\
IVb & Formal combination of expert views & B-
\end{tabular}

It is essential that potentially life-threatening illnesses such as Community Acquired Pneumonia (CAP) are diagnosed and managed rapidly, yet given the nature of primary care consultations, the identification and management of adults presenting with pneumonia is a major challenge for primary care health professionals.

The British Thoracic Society (BTS) CAP Guidelines, published in October 2009, ${ }^{2}$ provide comprehensive detailed evidence-based information on the management of CAP in adults. Systematic electronic database searches were conducted in order to identify potentially relevant studies that might inform guideline recommendations. Generic study appraisal checklists and an evidence grading from $A+$ to $D$ were used to indicate the strength of the evidence upon which recommendations were made. Of note, the Guidelines do not apply to patients who are immunosuppressed, nor do they apply to the larger group of adults with non-pneumonic lower respiratory tract infection - which includes illnesses labelled as acute bronchitis, acute exacerbations of COPD, or "chest infections".

In order to promote wider dissemination in primary care, and with permission from the publisher and editors of Thorax, this paper summarises the key recommendations from the full BTS Guidelines, and draws together recommendations and text relevant to primary care. It has been endorsed by both the Royal College of General Practitioners (RCGP) and the Primary Care Respiratory Society UK (PCRS-UK).

The evidence grading system used in developing the full Guidelines is shown in Table 1, and in this summary paper the evidence grading is shown in blue adjacent to the appropriate text or reference number.

\section{Definition}

For the purpose of these Guidelines, ${ }^{2}$ community acquired pneumonia (CAP) has been defined as:

- Symptoms of an acute lower respiratory tract illness (cough and at least one other lower respiratory tract symptom)

- New focal chest signs on examination
- Evidence of systemic illness (temperature $\geq 38^{\circ} \mathrm{C}$ and/or the symptom complex of sweating, fevers, shivers, aches and pains).

- No other explanation for the illness, and a clinical decision that it should be treated as community acquired pneumonia with antibiotics.

\section{Burden of disease}

In prospective population studies, the annual incidence of CAP in the community has been reported as 5-11 per 1000 adult population. ${ }^{3-5}$ Pneumonia, diagnosed clinically by GPS, accounts for only $5-12 \%$ of all cases of adult lower respiratory tract infection treated with antibiotics by GPs in the community in the UK. ${ }^{3,6}$ In the UK, $22-42 \%$ of adults with CAP are admitted to hospital. ${ }^{3,7}$

The reported mortality of adults with CAP managed in the community in the UK is very low and less than $1 \% .^{3,8,9}$ The direct costs associated with CAP are high and are mostly associated with inpatient care costs. ${ }^{7}$

Streptococcus pneumoniae is the commonest causative organism in CAP in all ages, accounting for about 36\% of cases of CAP diagnosed in the community. ${ }^{10}$ Mycoplasma pneumoniae and legionella infection are less frequent in the elderly, ${ }^{11,12}$ while Haemophilus influenzae may be more commonly identified in the elderly. ${ }^{13}$

\section{Prevention and vaccination}

Cigarette smoking, both active and passive, is a recognised independent risk factor for CAP. ${ }^{14,15}[\mathrm{lb}]$ Dose-response relationships with the current number of cigarettes smoked per day, pack-years of smoking, and time since quitting, have all been demonstrated in relation to invasive pneumococcal disease. ${ }^{15,16[I I I]}$

\section{Recommendations:}

- Smoking cessation advice should be offered to all patients with community acquired pneumonia who are current smokers, according to smoking 
cessation guidelines issued by the Health Education Authority. ${ }^{17}[\mathrm{~B}+]$

- Department of Health guidelines in relation to influenza and pneumococcal immunisation of 'at-risk' individuals should be followed. [C]

\section{Diagnosis of community acquired pneumonia in the community}

In the UK, most CAP is managed in primary care, where access to rapid chest radiography is limited. Consequently, in contrast with the hospital setting - where the diagnosis of CAP is confirmed by chest radiographic features - diagnosis in the community will often be based only on the clinical features. In this challenging setting, clinicians have to differentiate those patients presenting with CAP from the majority of patients who have acute, nonpneumonic lower respiratory tract infections or other diagnoses. ${ }^{4,18}[\mathrm{lb}]$

The typical patient history of cough, fever and dyspnoea with chest pains, and lung crackles on examination, is not reliable in discriminating CAP from other acute lower respiratory tract infections. ${ }^{19}[\mathrm{II}]^{20}[\mathrm{la}]^{21}[\mathrm{la}]$

Various prediction rules have been published for the diagnosis of CAP, but generally these have shown the need for confirmatory radiographic evidence. Nevertheless, some helpful pointers in the diagnosis of CAP have been reported:

a) Woodhead et $a .^{3}[\mathrm{II}]$ reported that in adults treated with antibiotics for an acute lower respiratory tract infection associated with new focal signs on chest examination, 39\% had evidence of CAP on chest radiograph.

b) Melbye et al. ${ }^{19}[\mathrm{II}]$ found that, of the clinical findings reported by GPs to be most suggestive to them of CAP, only a short duration of symptoms ( $<24 \mathrm{~h}$ ) was of significant predictive value.

c) In a study of 1819 adults presenting to hospital outpatients with acute cough, Diehr et al.22 [II] showed that the presence of fever $\left(>37.8^{\circ} \mathrm{C}\right)$, raised respiratory rate $(>25$ breaths $/ \mathrm{min})$, sputum production throughout the day, myalgia and night sweats, plus the absence of sore throat and rhinorrhoea, predicted CAP in a diagnostic rule with $91 \%$ sensitivity and $40 \%$ specificity.

d) Another study conducted in patients presenting with acute respiratory symptoms to outpatient clinics and the emergency department in California determined that the presence of either abnormal vital signs (fever $>38^{\circ} \mathrm{C}$, tachycardia $>100 /$ min and tachypnoea $>20 /$ min) or an abnormal physical examination of the chest (crackles, decreased breath sounds, dullness to percussion, wheeze) identified patients with radiographically confirmed CAP with a sensitivity of 95\%, negative predictive value of $92 \%$ and specificity of $56 \%{ }^{23}[\mathrm{II}]$

e) In elderly patients, the classic symptoms and signs of pneumonia are less likely, and non-specific features - especially confusion - are more likely. ${ }^{24-28[I I] ~ I n ~ a d d i t i o n, ~}$ absence of fever is more common compared to younger patients with CAP. ${ }^{29,30}[\mathrm{II}]$

In practice, GPs manage the vast majority of patients pragmatically at first presentation. The important decision in patients presenting with a lower respiratory tract infection, or suspected CAP, is deciding whether to use an antibiotic, which one, and how ill the patient is. Labelling the illness as pneumonia is less important. ${ }^{31}$

\section{Severity assessment and site of care}

The decision regarding the most appropriate site of care - in particular, whether hospitalisation of a patient with CAP is warranted - is the first and single most important decision in the overall management of CAP. It has consequences on both the level of treatment received by the patient as well as the overall costs of treatment. [III] This decision is best informed firstly by an accurate assessment of the severity of illness at presentation (and hence the likely prognosis), and secondly by other factors such as the stability of other co-morbid illnesses and the social circumstances of the patient.

\section{The CRB-65 score}

The clinical judgement of the GP will be crucial in assessing the severity of illness, but this can be aided by the simple CRB65 severity assessment tool. The CRB-65 score is a practical, validated tool which provides a clinician in a community setting with an assessment of the severity of CAP based on mortality risk. ${ }^{32,33}$ The score is based on the presence of confusion, ${ }^{34}$ raised respiratory rate, low blood pressure and the age of the patient (see Figure 1).

The recognition of patients at low risk of complications - who are therefore suitable for treatment outside hospital - has the potential to reduce inappropriate hospitalisation and consequently inherent morbidity and costs. Ultimately, the decision to manage a patient in the community is based on a range of factors which include an assessment that the pneumonia is of low severity, that oral therapy is appropriate and will be complied with, and that the social circumstances and available care for an individual are satisfactory.

\section{Recommendations:}

- For all patients, clinical judgement should be supported by the CRB-65 score (see Figure 1) when deciding whether to treat the patient at home or in hospital. [D]

- Patients who have a CRB-65 score of 0 are at low risk of death and do not normally require hospitalisation for clinical reasons. $[\mathrm{B}+]$

- Patients who have a CRB-65 score of 1 or 2 are at increased risk of death, particularly those patients 
ML Levy et al.

Figure 1. Severity assessment of community acquired pneumonia in the community (adapted from ref 34).

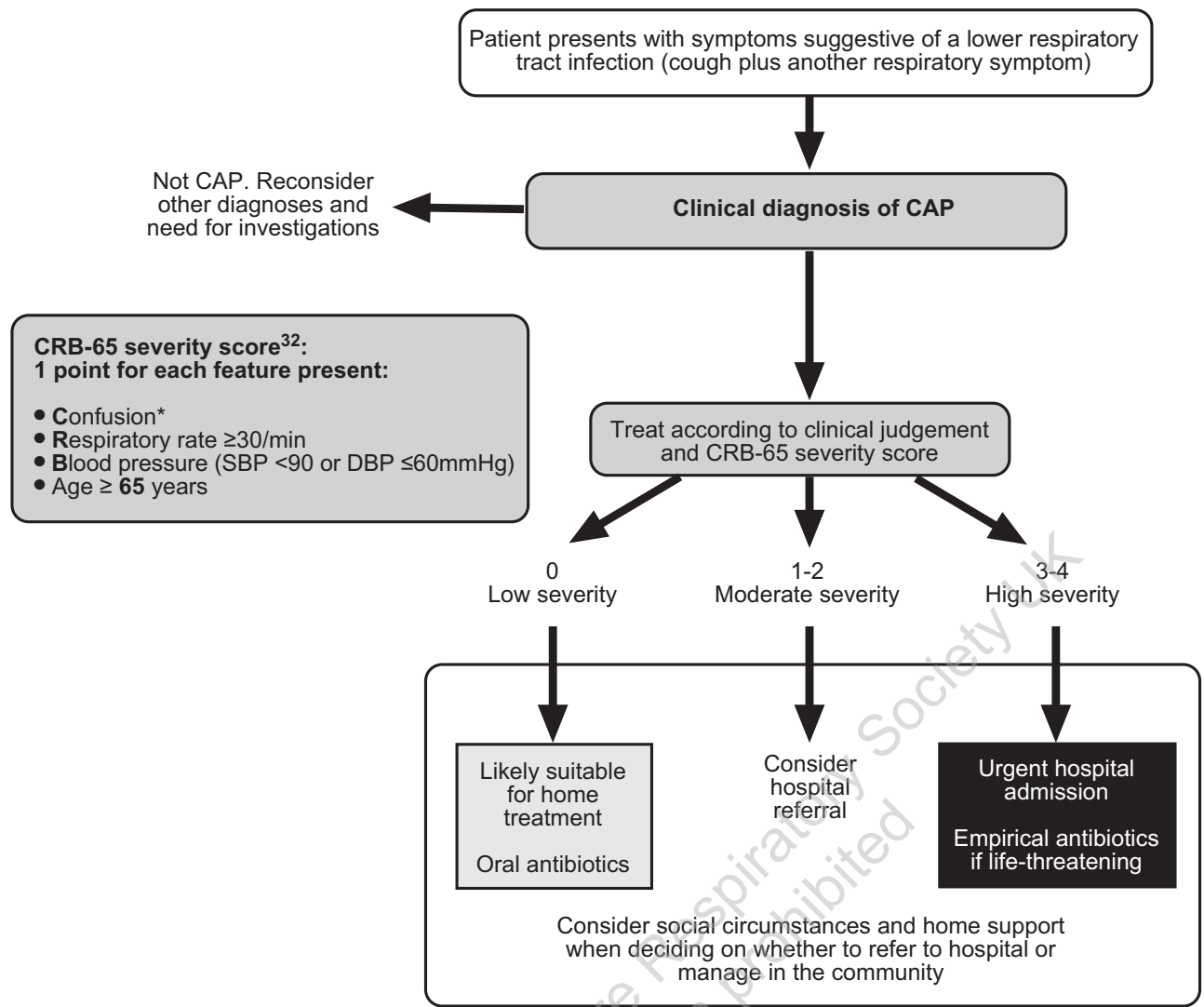

ABBREVIATED MENTAL TEST ${ }^{34}$ (each question scores 1 mark, total 10 marks)

Age

Recognition of two persons (eg doctor, nurse)

Date of birth

Recall address (eg 42 West Street)

Time (to nearest hour)

Date of First World War

Year

Name of Monarch

Address or location ("Where are you?")

Count backwards $20-1$

${ }^{*}$ A score of 8 or less has been used to define mental confusion in the CRB-65 severity score

$\mathrm{SBP}=$ systolic blood pressure; $\mathrm{DBP}=$ diastolic blood pressure

with Score 2, and hospital referral and assessment should be considered. [B+]

- Patients who have a CRB-65 score of 3 or more are at high risk of death and require urgent hospital admission. [B+]

- When deciding on home treatment, the patient's social circumstances and wishes must be taken into account in all instances. [D]

\section{Investigations}

General investigations may be performed for the following reasons: to assess severity; to assess the impact on, or to detect the presence of, any co-morbid disease; to provide some pointer to the particular aetiological agent or group of pathogens; to identify complications; and to monitor progress. Pulse oximeters allow for simple assessment of oxygenation.

Most patients with pneumonia are treated successfully in the community in the absence of any microbial definition of an infecting micro-organism(s). Many microbiological investigations will not be appropriate for patients with CAP managed in the community. Such patients are not usually severely ill, are at low risk of death, and delays in transport of specimens to the laboratory reduces the yield of bacterial pathogens (especially $S$ pneumoniae) from sputum cultures. Results are also often received too late by the GP for them to be of much practical value in initial management. 


\section{Recommendations:}

- General investigations (like full blood counts) are not necessary for the majority of patients with community acquired pneumonia who are managed in the community. [C]

- Pulse oximetry, with appropriate training, should be available to GPs and other clinicians responsible for the assessment of patients in the out-of-hours setting for the assessment of severity and oxygen requirement in patients with CAP and other acute respiratory illnesses. [D]

- Patients without pre-exisiting co-morbid medical conditions who have an oxygen saturation $<94 \%$ should be considered for hospital referral and oxygen supplementation. ${ }^{35}$

- Pulse oximetry should be available in all locations where emergency oxygen is used. [D]

- For patients managed in the community microbiological investigations are not recommended routinely. [D]

- Examination of sputum should be considered for patients who do not respond to empirical antibiotic therapy. [D]

- Examination of sputum for Mycobacterium tuberculosis should be considered for patients with a persistent productive cough, especially if they have malaise, weight loss or night sweats, or if risk factors for tuberculosis (e.g. ethnic origin, social deprivation, the elderly) are present. [D]

- Urine antigen investigations (for $S$ pneumoniae or Legionella pneumophilia), PCR of upper (e.g. nose and throat swabs) or lower (e.g. sputum) respiratory tract samples, or serological investigations (for a range of respiratory viruses and some atypical pathogens such as Mycoplasma pneumoniae) may be considered during outbreaks (e.g. Legionnaires' disease), during mycoplasma epidemic years, or when there is a particular clinical or epidemiological reason. [D]

\section{Chest $X$ Ray}

- It is not necessary to perform a chest radiograph in patients with suspected CAP unless:
a) The diagnosis is in doubt and a chest radiograph will help in the differential diagnosis and management of the acute illness. [D]
b) Progress following treatment for suspected CAP is not satisfactory at review. [D]
c) The patient is considered at risk of underlying lung pathology. [D]

\section{General and antibiotic management}

Unlike some other respiratory infections (e.g. acute bronchitis), ${ }^{36}$ an antibiotic is always indicated when a clinical diagnosis of pneumonia is made. Empirical therapy is primarily directed at $S$ pneumoniae which remains the leading cause of CAP. [la]

From time to time, GPs see patients who are severely ill with what appears to be pneumonia. There is direct and indirect evidence that administering antibiotics early is important in the outcome of CAP, particularly when the patient is assessed as being severely ill. ${ }^{37-39}[\mathrm{Ib}]$ In the UK, less than half of patients admitted with high severity CAP have received antibiotics from their GP. ${ }^{40,41}[$ [II] Prescribing antibiotics does have an influence on some microbiological investigations. ${ }^{42}[\mathrm{lb}]$ However, when GPs feel that a patient is severely ill, or circumstances suggest that delays in transfer will slow assessment and treatment in hospital, concern over the potential effect on subsequent investigations is not a reason to withhold treatment.

\section{Recommendations:}

- Patients with suspected CAP should be advised not to smoke, to rest, and to drink plenty of fluids. [D]

- Pleuritic pain should be relieved using simple analgesia such as paracetamol. [D]

- For patients treated in the community, amoxicillin remains the preferred agent at a dose of $500 \mathrm{mg}$ three times daily. $[\mathrm{A}+]$

- Either doxycycline (200mg loading dose then $100 \mathrm{mg}$ daily) [D] or clarithromycin (500 mg twice daily) [A-] are appropriate as an alternative choice, and for those patients who are hypersensitive to penicillins.

- For patients managed in the community, seven days of appropriate antibiotics is recommended. [C]

- For those patients referred to hospital with suspected CAP and where the illness is considered to be lifethreatening, GPs should administer antibiotics in the community. [D] Penicillin G 1.2g intravenously or amoxicillin $1 \mathrm{~g}$ orally are the preferred agents.

- For those patients referred to hospital with suspected high severity CAP and where there are likely to be delays of over six hours in the patient being admitted and treated in hospital, GPs should consider administering antibiotics in the community. [D]

\section{Patient review and follow-up arrangements}

Patients should be informed about the expected rate of resolution of their symptoms and any X-ray changes that have been found (in those who had this investigation). In most patients, symptoms and chest X-ray abnormalities resolve within six weeks. In the elderly, radiographic clearance is slower. 
When to review a patient with CAP in the community will be determined by the initial severity assessment and other factors such as the help available in the home setting. Patients assessed as being at low severity should improve on appropriate therapy within 48 hours, at which time severity reassessment is recommended. Those who fail to improve within 48 hours should be considered for hospital admission. Patients who do not fulfil the criteria for low severity and are being managed at home will require more frequent review.

For patients discharged from hospital, it is usual practice to arrange "routine" hospital clinic follow-up and repeat the chest radiograph at around six weeks after discharge. However, there is no evidence on which to base a recommendation regarding the value of this practice in patients who have otherwise recovered satisfactorily. It is also not known whether there is any value in arranging clinical follow-up in a hospital clinic rather than with the patient's GP. The main concern is whether or not the CAP was a complication of an underlying condition such as lung cancer. Therefore, it seems sensible to arrange a clinical review of all patients at around six weeks, either with their GP or in a hospital clinic. If clinical or radiographic resolution is delayed, referral to a specialist may be appropriate.

\section{Recommendations:}

- Review of patients in the community with CAP is recommended after 48 hours, or earlier if clinically indicated. Disease severity assessment should form part of the clinical review. [D]

- Those who fail to improve after 48 hours of treatment should be considered for hospital admission or chest radiography. [D]

- For patients discharged from hospital, it is the responsibility of the hospital team to arrange the follow-up plan with the patient and the GP. [D]

- At discharge or at follow-up, patients should be offered access to information about CAP such as a Patient Information Leaflet (PIL). [D] A PIL on CAP is available on request from the British Lung Foundation Headquarters (British Lung Foundation, Freepost SW1233, London EC1B 1BR) and British Lung Foundation UK regional offices, or from the Clinical Knowledge Summaries (CKS) webpage provided by the NHS Institute for Innovation and Improvement. [http://www.cks.nhs.uk/patient_information_leaflet/ pneumonia]

\section{Conclusions}

This summary of the BTS CAP Guidelines originally published in October $2009^{2}$ provides definitions, summaries of key messages, and recommendations for handling the uncertainty of the clinical diagnosis, assessing severity, management, and follow-up of patients with CAP in the community setting. Diagnosis and decision on hospital referral in primary care should be based on clinical judgement and the CRB-65 score. An antibiotic is always indicated when a clinical diagnosis of pneumonia is made. When there is delay in symptom or radiographic resolution beyond six weeks, the main concern is whether the CAP was a complication of an underlying condition such as lung cancer.

\section{Acknowledgements}

We thank Sally Welham, Deputy Chief Executive of the BTS, for wise advice and expertise in the development of this Summary document; Dr Helen Roberts for considerable help with the references; and both Dr John White, Chairman BTS Standards of Care Guidelines Committee, and Professor Wisia Wedzicha, Editor-inChief of Thorax, for their continued support from the inception of this Summary.

\section{Conflict of Interest declarations}

MLL has accepted sponsorship from GlaxoSmithKline (GSK), AstraZeneca (AZ), Boehringer Ingelheim, Trinity-Cheisi, Merck Sharpe and Dohme (MSD), Merck, Altana Pharma, Novartis, Meda Pharmaceuticals, 3M Pharmaceuticals, Schering Plough for attending conferences. He has accepted lecture fees from Boehringer Ingelheim, GSK, AZ and Alk-Abello. He has been on advisory boards or provided consultancy for GSK, Schering Plough, MSD, Trinity-Cheisi, Altana Pharma, Ranbaxy, AZ, 3M Pharmaceuticals and Novartis. He has had research grants from Boehringer Ingelheim, Pfizer, GSK. He is a member of the ADMIT Group, which receives an unrestricted educational grant from MEDA pharmaceuticals. He is the Editor-inChief of the PCRJ, but was not involved in the editorial review of, nor the decision to publish, this article.

ILJ no conflicts of interest to declare.

MW declares that he has received reimbursement from Wyeth as a paid member of a Trial Data Monitoring Committee.

JTM no conflicts of interest to declare.

WSL no conflicts of interest to declare.

\section{References}

1. Levy ML. Guideline-defined asthma control: a challenge for primary care. Eur Respir J 2008;31(2):229-31. http://dx.doi.org/10.1183/09031936.00157507

2. Lim WS, Baudouin SV, George RC, et al. BTS guidelines for the management of community acquired pneumonia in adults: update 2009. Thorax 2009;64 Suppl 3:iii1-55. http://dx.doi.org/10.1136/thx.2009.121434

3. Woodhead MA, Macfarlane JT, McCracken JS, Rose DH, Finch RG. Prospective study of the aetiology and outcome of pneumonia in the community. Lancet 1987;1(8534):671-4. http://dx.doi.org/10.1016/S0140-6736(87)90430-2

4. Jokinen $\mathrm{C}$, Heiskanen $\mathrm{L}$, Juvonen $\mathrm{H}$, et al. Incidence of community-acquired pneumonia in the population of four municipalities in eastern Finland. Am $J$ Epidemiol 1993;137(9):977-88

5. Foy HM, Cooney MK, Allan I, Kenny GE. Rates of pneumonia during influenza epidemics in Seattle, 1964 to 1975. JAMA 1979;241(3):253-8.

6. Macfarlane JT, Colville A, Guion A, Macfarlane RM, Rose DH. Prospective study of aetiology and outcome of adult lower-respiratory-tract infections in the community. Lancet 1993;341(8844):511-14. http://dx.doi.org/10.1016/01406736(93)90275-L

7. Guest JF, Morris A. Community-acquired pneumonia: the annual cost to the National Health Service in the UK. Eur Respir J 1997;10(7):1530-4.

8. Department of Health. The NHS Plan: a plan for investment, a plan for reform. 2000.

9. Minogue MF, Coley CM, Fine MJ, Marrie TJ, Kapoor WN, Singer DE. Patients hospitalized after initial outpatient treatment for community-acquired pneumonia. Ann Emerg Med 1998;31(3):376-80. http://dx.doi.org/ 10.1016/S0196-0644(98)70350-6

10. Lim I, Shaw DR, Stanley DP, Lumb R, McLennan G. A prospective hospital study of the aetiology of community-acquired pneumonia. Med J Aust 
1989;151(2):87-91.

11. Lim WS, Macfarlane JT, Boswell TC, et al. Study of community acquired pneumonia aetiology (SCAPA) in adults admitted to hospital: implications for management guidelines. Thorax 2001;56(4):296-301. http://dx.doi.org/ 10.1136/thorax.56.4.296

12. Venkatesan P, Gladman J, Macfarlane JT, et al. A hospital study of community acquired pneumonia in the elderly. Thorax 1990;45(4):254-8. http://dx.doi.org/ 10.1136/thx.45.4.254

13. Ausina $V$, Coll $P$, Sambeat $M$, et al. Prospective study on the etiology of community-acquired pneumonia in children and adults in Spain. Eur J Clin Microbiol Infect Dis 1988;7(3):342-7. http://dx.doi.org/10.1007/BF01962334

14. Almirall J, Bolibar I, Serra-Prat M, et al. New evidence of risk factors for community-acquired pneumonia: a population-based study. Eur Respir J 2008;31(6):1274-84. http://dx.doi.org/10.1183/09031936.00095807

15. Baik I, Curhan GC, Rimm EB, Bendich A, Willett WC, Fawzi WW. A prospective study of age and lifestyle factors in relation to community-acquired pneumonia in US men and women. Arch Intern Med 2000;160(20):3082-8. http://dx.doi.org/10.1001/archinte.160.20.3082

16. Nuorti JP, Butler JC, Farley MM, et al. Cigarette smoking and invasive pneumococcal disease. Active Bacterial Core Surveillance Team. N Engl J Med 2000;342(10):681-9. http://dx.doi.org/10.1056/NEJM200003093421002

17. West R, McNeill A, Raw M. Smoking cessation guidelines for health professionals: an update. Health Education Authority. Thorax 2000;55(12):987-99. http://dx.doi.org/10.1136/thorax.55.12.987

18. Macfarlane J. Lower respiratory tract infection and pneumonia in the community. Semin Respir Infect 1999;14(2):151-62.

19. Melbye H, Straume B, Aasebø U, Brox J. The diagnosis of adult pneumonia in general practice. The diagnostic value of history, physical examination and some blood tests. Scand J Prim Health Care 1988;6(2):111-17. http://dx.doi.org/10.3109/02813438809009300

20. Metlay JP, Kapoor WN, Fine MJ. Does this patient have community-acquired pneumonia? Diagnosing pneumonia by history and physical examination. JAMA 1997;278(17):1440-5. http://dx.doi.org/10.1001/jama.278.17.1440

21. Metlay JP, Fine MJ. Testing strategies in the initial management of patients with community-acquired pneumonia. Annals of Internal Medicine 2003;138(2):109-18.

22. Diehr P, Wood RW, Bushyhead J, Krueger L, Wolcott B, Tompkins RK. Prediction of pneumonia in outpatients with acute cough--a statistical approach. J Chronic Dis 1984;37(3):215-25. http://dx.doi.org/10.1016/0021-9681(84)90149-8

23. O'Brien WT, Sr., Rohweder DA, Lattin GE, Jr., et al. Clinical indicators of radiographic findings in patients with suspected community-acquired pneumonia: who needs a chest x-ray? J Am Coll Radiol 2006;3(9):703-06. [erratum appears in $J$ Am Coll Radiol 2006;3(10):A4]. http://dx.doi.org/10.1016/j.jacr.2006.02.007

24. Marrie TJ. Pneumonia in the elderly. Curr Opin Pulm Med 1996;2(3):192-7. http://dx.doi.org/10.1097/00063198-199605000-00006

25. Metlay JP, Schulz R, Li YH, et al. Influence of age on symptoms at presentation in patients with community-acquired pneumonia. Arch Intern Med 1997;157(13):1453-9.

26. Riquelme R, Torres A, el-Ebiary M, et al. Community-acquired pneumonia in the elderly. Clinical and nutritional aspects. Am J Respir Crit Care Med 1997;156(6):1908-14.

27. Fernandez-Sabe N, Carratala J, Roson B, et al. Community-acquired pneumonia in very elderly patients: causative organisms, clinical characteristics, and outcomes. Medicine 2003;82(3):159-69. http://dx.doi.org/10.1097/00005792200305000-00002

28. Riquelme R, Torres A, El-Ebiary M, et al. Community-acquired pneumonia in the elderly: A multivariate analysis of risk and prognostic factors. Am J Respir Crit Care Med 1996;154(5):1450-5.

29. Marrie TJ, Haldane EV, Faulkner RS, Durant H, Kwan C. Community-acquired pneumonia requiring hospitalization. Is it different in the elderly? J Am Geriatr Soc 1985;33(10):671-80.

30. Fang GD, Fine M, Orloff J, et al. New and emerging etiologies for communityacquired pneumonia with implications for therapy. A prospective multicenter study of 359 cases. Medicine (Baltimore) 1990;69(5):307-16. http://dx.doi.org/10.1097/00005792-199009000-00004

31. Macfarlane J, Holmes W, Gard P, et al. Prospective study of the incidence, aetiology and outcome of adult lower respiratory tract illness in the community. Thorax 2001;56(2):109-14. http://dx.doi.org/10.1136/thorax.56.2.109

32. Lim WS, van der Eerden MM, Laing R, et al. Defining community acquired pneumonia severity on presentation to hospital: an international derivation and validation study. Thorax 2003;58(5):377-82. http://dx.doi.org/10.1136/ thorax.58.5.377

33. Bauer TT, Ewig S, Marre R, Suttorp N, Welte T, The CSG. CRB-65 predicts death from community-acquired pneumonia. J Int Med 2006;260(1):93-101. http://dx.doi.org/10.1111/j.1365-2796.2006.01657.x

34. Qureshi KN, Hodkinson HM. Evaluation of a ten-question mental test in the institutionalized elderly. Age Ageing 1974;3(3):152-7. http://dx.doi.org/ 10.1093/ageing/3.3.152

35. BritishThoracicSociety. BTS guideline for emergency oxygen use in adult patients. Thorax 2008;63 Suppl 6:vi1-68. http://dx.doi.org/ 10.1136/thx.2008.102947

36. NICE. Nice Clinical Guideline 69. Respiratory tract infections - antibiotic prescribing Prescribing of antibiotics for self-limiting respiratory tract infections in adults and children in primary care.

37. Meehan TP, Fine MJ, Krumholz HM, et al. Quality of care, process, and outcomes in elderly patients with pneumonia. JAMA 1997;278(23):2080-4.

38. Houck PM, Bratzler DW, Nsa W, Ma A, Bartlett JG. Timing of antibiotic administration and outcomes for Medicare patients hospitalized with community-acquired pneumonia. Arch Int Med 2004;164(6):637-44. http://dx.doi.org/10.1001/archinte.164.6.637

39. Marston BJ, Plouffe JF, File TM, Jr., et al. Incidence of community-acquired pneumonia requiring hospitalization. Results of a population-based active surveillance Study in Ohio. The Community-Based Pneumonia Incidence Study Group. Arch Intern Med 1997;157(15):1709-18.

40. The aetiology, management and outcome of severe community-acquired pneumonia on the intensive care unit. The British Thoracic Society Research Committee and The Public Health Laboratory Service. Respir Med 1992;86(1):713.

41. Hirani NA, Macfarlane JT. Impact of management guidelines on the outcome of severe community acquired pneumonia. Thorax 1997;52(1):17-21. http://dx.doi.org/10.1136/thx.52.1.17

42. British Thoracic Society. Community-acquired pneumonia in adults in British hospitals in 1982-1983: a survey of aetiology, mortality, prognostic factors and outcome. Q J Med 1987;62(239):195-220.

Available online at http://www.thepcrj.org 